\title{
Delayed development in the short-tailed fruit bat, Carollia perspicillata
}

\author{
J. J. Rasweiler IV and N. K. Badwaik \\ Department of Obstetrics and Gynecology, Cornell University Medical College, 1300 York Avenue, \\ New York, 10021, USA
}

\begin{abstract}
Pregnancy was studied in short-tailed fruit bats, Carollia perspicillata, both maintained in a captive breeding colony and collected from a reproductively synchronized wild population on the island of Trinidad. Gestation periods for captive females that successfully reared their young varied as follows: mated at a regular oestrus during their first year in captivity (105-178 days) (mean \pm SD: $145 \pm 19$ days); mated at a postpartum oestrus during their first year in captivity (110-158 days) (133 \pm 16 days); mated during their second year in captivity (113-169 days) (127 \pm 12 days); females born and mated in captivity (113-159 days) (119 \pm 9 days). Most females in the last group had gestation periods of 113-119 days; this may represent the normal (nondelayed) gestation period for the species. Histological studies established that most of the observed variation in duration of gestation was due to delays occurring after the completion of implantation. It seems likely that stress, rather than age, was responsible for the prolongation of pregnancy in some animals, because this occurred less frequently in both younger and older females. There may be stressful situations in the wild (for example, lack of sufficient food or roosting sites) in which the ability to delay pregnancies would be of considerable adaptive value. Evidence was obtained that under some circumstances Carollia can extend gestation even further. Many wildcaught females successfully gave birth at 160-229 days after being isolated from breeding males in captivity. These had been captured at the time of year when, based upon subsequent histological studies of field collected specimens, most adult females should have been in early pregnancy. The field studies have also provided evidence that females in the wild population exhibit a seasonal prolongation of pregnancy.
\end{abstract}

\section{Introduction}

Embryonic diapause has been observed in seven orders of mammals (Marsupialia, Insectivora, Chiroptera, Edentata, Carnivora, Rodentia and Artiodactyla) and, in most species, occurs before implantation (delayed implantation; Mead, 1993). In bats, embryonic diapause also occurs after implantation (delayed development) in representatives of at least five different families - the Emballonuridae (Krishna and Dominic, 1982), Phyllostomidae (Bradshaw, 1962; Fleming, 1971; Bodley, 1974; Bleier, 1975), Pteropodidae (Heideman, 1989), Rhinolophidae (Bhiwgade, 1979; Bernard and Meester, 1982; Sapkal and Bhandarkar, 1984) and Vespertilionidae (Racey, 1969; Racey and Swift, 1981; Kimura and Uchida, 1983; Crichton et al., 1989) - and there is evidence that suggests that it may take place in a member of the family Natalidae (Mitchell, 1965; Wimsatt, 1975).

During the course of work with captive maintained shorttailed fruit bats (Carollia perspicillata) considerable variation in duration of gestation was noted. This was found to be attributable to the occurrence of developmental delays after the initiation of implantation and was, to some extent, susceptible to experimental manipulation.

Received 12 February 1996
Materials and Methods

\section{Animals and treatments}

All of the short-tailed fruit bats (Carollia perspicillata) used in this study were either collected in the wild on the West Indian island of Trinidad or reared in captivity. The captive maintained animals were kept in a locked, restricted access room, and a continued effort was made to minimize disturbing them. The room had a controlled light cycle ( $12 \mathrm{~h}$ light: $12 \mathrm{~h}$ dark), with the dark phase set to commence at 16:00 h to facilitate feeding just before its onset. The temperature was generally maintained between 24 and $27^{\circ} \mathrm{C}$; however, during two experiments (noted below) the heating and ventilation systems serving the animal quarters malfunctioned on several occasions. This created undesirable temperature gradients in the animal room and probably caused premature spoilage of the bats' food in at least some of the cages.

The bats were housed in bipartite cages, approximately $170 \mathrm{~cm}$ wide $\times 81 \mathrm{~cm}$ high $\times 77 \mathrm{~cm}$ deep, which permitted the animals to fly. The cages were subdivided into an open feeding area ( $92 \mathrm{~cm}$ wide) and a darkened roosting box connected by an access hole ( $15 \mathrm{~cm}$ high $\times 30 \mathrm{~cm}$ wide). The bats were maintained in sexually segregated groups composed of 8-12 males or 10-20 females until the time of mating. They were fed 
a fruit-based liquid diet prepared from readily available canned and powdered components (peach nectar, canned peaches, ground monkey chow, dibasic calcium phosphate, corn oil, an emulsifier and a multivitamin preparation). This was occasionally supplemented with small amounts of banana or apple as treats. The animals were fed every night, and the diet was served cold, usually no more than $60-90 \mathrm{~min}$ before the room lights went off, to minimize microbial growth. Water was provided ad libitum in chick waterers (Rasweiler and Badwaik, 1996).

\section{Timing of reproductive stages}

For breeding purposes, a single male with prominent testes was added to each group of 10-18 females. On subsequent mornings, between $05: 30 \mathrm{~h}$ and $09: 00 \mathrm{~h}$, a small quantity of distilled water was aspirated in the vagina of each female with a microeyedropper. The aspirate was then dried and examined for spermatozoa. Most females exhibited a single period of sperm-positive vaginal aspirates that usually varied from $1-5$ days in duration (Rasweiler and Badwaik, 1996). In some cases, females exhibited two separate periods of sperm-positive smears. For such females in early pregnancy, the probable time of conception could be identified from an examination of their breeding records and the stage of development of their embryos (determined histologically). This could not be done for females in advanced pregnancy or when they were permitted to give birth. When there was uncertainty about the time of conception, the females were not included in the results reported here. Mated females were killed between 06:30 h and $10: 30 \mathrm{~h}$ at various intervals after the first morning on which spermatozoa were detected in their vaginal aspirates (day I after mating), or were permitted to give birth. Animals were killed by the administration of an intraperitoneal injection of sodium pentobarbital at a dose of approximately $90 \mathrm{mg} \mathrm{kg}^{-1}$ body mass.

Because fertilization had not yet occurred in Carollia examined on day 1 after mating in a previous study (Bonilla and Rasweiler, 1974), all gestation periods (except minimum possible gestation periods, as defined below) were obtained by subtracting one day from the day after mating. In addition, the recorded time of birth may have varied from the actual time of birth by up to $24 \mathrm{~h}$ because, to minimize disturbance of the animals, they were checked only once per day for newborns. All reported gestation periods are for females that successfully reared their young.

\section{Gestation periods for wild caught, captive bred bats}

Only wild caught females of unknown age that had attained adult body size were introduced into captivity for this work.

\section{Gestation periods for captive reared, captive bred bats}

As part of an effort to determine whether gestation period is affected by age, parity or stress, some captive reared animals were mated. All were $<2$ years old and, with the exception of two females, nonparous when mated. One group of these bats was unintentionally exposed to presumably stressful environmental conditions when the heating and ventilation systems in the animal quarters malfunctioned. This damaged experiment was therefore repeated using new animals.

\section{Social groupings during pregnancy}

Most observations on conceptus development or duration of gestation were obtained for females maintained in reasonably stable social groupings that were altered only by the removal of the father and sometimes of females from the grouping. The only exceptions to this were among the captive reared females. Some $(n=6)$ were mated in the same way, but used in another experiment that involved normal nonmanipulated animals. Efficient management of the colony required that these leftover females were moved to completely new social groupings during early pregnancy. Others $(n=15)$ were mated and then moved on day 5 after mating to new, smaller groupings of five animals per cage. These were control animals for an experiment requiring small groupings.

\section{Assessment of reproductive condition}

After fixation of the reproductive tract, the greatest diameter (that is, the transverse dimension) of the uterine corpus was measured. This does not fully reflect the increasing size of the fetus as pregnancy progresses, because the fetuses become oriented longitudinally within the uterus. The fetuses were then dissected out, weighed, and their crown-rump lengths measured. All reproductive tracts with maximum uterine diameters $<5.0 \mathrm{~mm}$ were serially sectioned and examined histologically. Bats with uterine diameters $\geq 5.0 \mathrm{~mm}$ either contained conceptuses that could be dissected out or were assumed to be pregnant (because all specimens $(n=8)$ with uterine diameters between 4.0 and $4.9 \mathrm{~mm}$ were found to be pregnant upon histological examination).

\section{Minimum possible gestation periods for pregnant, wild caught bats}

During November 1991 and October 1993 female Carollia were collected in the wild and then maintained in all female groupings in captivity. In the light of a previous field study carried out on Trinidad (Deoraj, 1987), it was assumed that the females in the first group would not be reproductively active at the time of capture. When efforts were initiated to breed these animals 3-4 months later, however, many were found to be already pregnant. Males were placed with some of these females in late pregnancy to obtain information on the timing of the postpartum oestrus in this species (Rasweiler and Badwaik, 1996). Other females in the 1991 group and all of those in the 1993 group were not housed with males.

As the work with the 1991 group was carried out before the variability in the duration of gestation in Carollia was known, the reproductive status of females was considered before housing some of them with males. Because this assignment of females was nonrandom, the influence (if any) of males upon duration of gestation in the 1991 females could not be analysed. Animals in the October 1993 group were unintentionally exposed to presumably stressful environmental 
conditions on several occasions during pregnancy owing to malfunctioning of the heating and ventilation systems. Observations for these two groups of wild caught females are nevertheless valuable, because they indicate that there are circumstances under which gestation periods can be significantly longer than were observed in captive bred animals.

\section{Reproductive status of females in the wild population}

Births subsequently recorded for the bats collected in October 1991 and November 1993 suggested that many may have been in early pregnancy when captured. The reproductive status of the wild population at this time of year was determined by randomly collecting 28 females of adult body size (14.85-18.57 g) from a large colony on Trinidad on 9 November 1995. Reproductive tracts were preserved for histological analysis, within $6 \mathrm{~h}$ of capture, from 15 females with mammary glands that showed signs of recent activity (that is, enlarged teats and a surrounding area either bare of fur or covered with new fur) and five of 13 females with mammary glands that had not been recently active.

Twenty additional adult females were collected from the same colony on I April 1996 to obtain information on the timing of parturition. After fixation, the greatest diameter of the uterine corpus in each female was measured. In the case of pregnant females, the fetuses were dissected out, weighed and their crown-rump lengths measured. In the case of lactating females, infant and maternal mass were measured separately.

\section{Infant mass on the day of birth}

This was determined for 12 infants delivered by captive bred mothers after untimed pregnancies. Masses purposely were not obtained for all newborn young, because of concern that the weighing procedure might increase the frequency with which such young are rejected by their mothers.

\section{Histological procedures}

The reproductive tracts of captive maintained animals that were examined histologically were fixed in Zenker's fluid for 8-10.5 h, immersed in $2.5 \%(\mathrm{w} / \mathrm{v})$ aqueous potassium dichromate for an additional $2 \mathrm{~h}$, washed overnight in running tap water, dehydrated through graded ethyl alcohols, cleared overnight in warm cedar wood oil $\left(37^{\circ} \mathrm{C}\right)$ and then by Histosol or Histoclear II (National Diagnostics, Inc., Atlanta, GA), and embedded in paraffin wax. The tracts were then serially sectioned (in a frontal plane) at $6 \mu \mathrm{m}$. The sections were stained with haematoxylin and eosin, Weigert's resorcin-fuchsin (Clifford and Taylor, 1973) and then Masson's trichrome procedure (modified from Humason, 1972; see Badwaik et al., in press), or by the periodic acid-Schiff (PAS) technique and counterstained with haematoxylin. Some sections of each tract were incubated for $1 \mathrm{~h}$ at $37^{\circ} \mathrm{C}$ in $0.1 \%(\mathrm{w} / \mathrm{v}) \alpha$-amylase (1,4- $\alpha$-D-glucan-glucanohydrolase; Sigma Chemical Company, St Louis, MO) dissolved in a $0.02 \mathrm{~mol}$ phosphate buffer $\mathrm{I}^{-1}$ $(\mathrm{pH}$ 6.0) to remove any glycogen before being processed according to the PAS procedure. Parallel sections were incubated under similar conditions in the buffer alone and then stained.
The reproductive tracts from females collected in the field in November 1995 were fixed in Bouin's solution, washed in multiple changes of $50 \%$ ethyl alcohol, and then processed to paraffin wax according to the procedure described above. These tracts were also serially sectioned at $6 \mu \mathrm{m}$ and stained with haematoxylin and eosin, or the PAS technique and haematoxylin. Some sections from each tract were incubated in $0.1 \%(w / v) \alpha$-amylase as above before being stained using the PAS technique.

\section{Statistical analysis}

Duration of gestation for different female groupings have been reported both as means \pm SD and as medians. Differences between the medians were compared using the Wilcoxon rank sum test and were considered to be significant at $P<0.05$.

\section{Results}

\section{Gestation periods for laboratory bred animals}

When Carollia were mated at a regular oestrus within 12 months of being captured in the wild (that is, during year 1), they exhibited gestation periods that varied from 105-178 days (Fig. Ia). Year 1 animals that conceived at a postpartum oestrus in captivity, and successfully reared their young while carrying the new pregnancy, had gestation periods of 110-158 days. The median duration of gestation for these two groups were not statistically different (Table 1).

When Carollia were bred between 12 and 24 months of capture (that is, during year 2), their gestation periods varied from 113 to 145 days with the exception of one animal that had a gestation period of 169 days (Fig. Ib). The median duration of gestation for these animals was significantly shorter (124 days) than that for year 1 animals bred at a regular oestrus (146 days; Table 1). Some of these animals had also given birth during their first year in captivity, and the duration of gestation for each pregnancy is listed (Table 2). Two of these females $(Y-2$ and $Y-8)$ carried nondelayed pregnancies during both years. The remainder exhibited a moderate to substantial prolongation of the pregnancy(ies) in one or both years.

The possible effects of age, parity and stress upon duration of gestation was determined by mating nonparous animals born and reared in captivity. In the first experiment (Fig. Ic), damaged by temperature problems in the animal room, the females exhibited less dispersion in duration of gestation (113-141 days) than did wild caught year 1 animals, and the median duration of gestation for the captive reared females was significantly less (125.5 days). There was little difference in duration of gestation between the animals in this damaged experiment and wild caught year 2 bats (Table 1). These captive reared females also exhibited a relatively high frequency of reproductive failures (one premature delivery and five young stillborn or rejected soon after birth), presumably due to being stressed, as compared with other female groups (Fig. I).

When this experiment was repeated with captive reared animals maintained under stable conditions, most exhibited gestation periods between 113 and 119 days (Fig. Id). Of the 
(a)

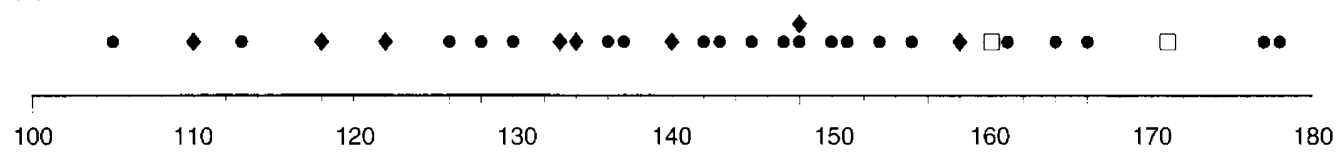

(b)
-8.8. 8. $.88 \cdot 08 \bullet 8 \cdot 0 \bullet \bullet$

\begin{tabular}{|c|c|c|c|c|c|c|c|}
\hline 100 & 110 & 120 & 130 & 140 & 150 & 160 & 170 \\
\hline
\end{tabular}

(c)

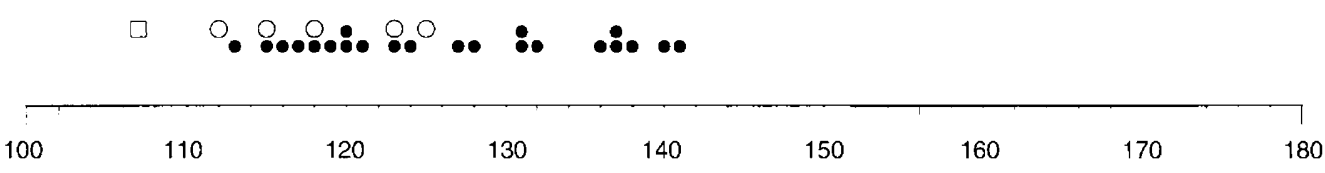

(d)

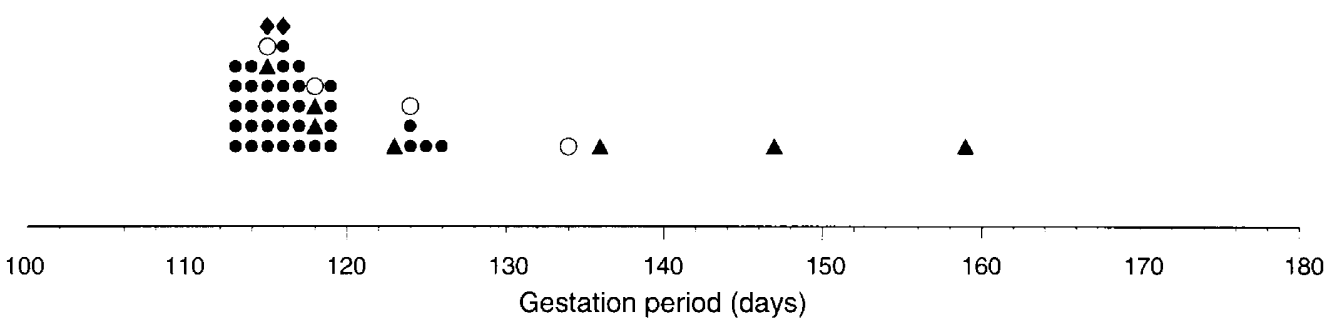

Fig. 1. Gestation period (days) for captive short-tailed fruit bats, Carollia perspicillata. (a) Females mated during their first year in captivity. (b) Females mated during their second year in captivity. (c) Captive reared and captive bred females, experiment damaged by unstable environmental temperature in the animal room. (d) Captive reared and captive bred females, stable animal room environment. ( $\bullet$ ) Conception associated with a regular oestrus. ( $\bullet$ Conception associated with a postpartum oestrus. ( $\mathbf{\Delta}$ ) Conception associated with a regular oestrus, females housed in 'exceptional' cage. (ב) Nonviable infant delivered prematurely. (O) Fully developed infant - stillborn or rejected at birth.

Table 1. Duration of gestation in the captive bred short-tailed fruit bat, Carollia perspicillata

\begin{tabular}{|c|c|c|c|c|c|}
\hline \multirow[b]{2}{*}{ Experimental group } & \multirow{2}{*}{$\begin{array}{c}\text { Number of } \\
\text { females }\end{array}$} & \multicolumn{4}{|c|}{ Duration of gestation (days) } \\
\hline & & Range & Mean & SD & Median \\
\hline Year 1 - wild-caught, mated at regular oestrus & 21 & $105-178$ & 145 & 19 & $146^{\mathrm{abcd}}$ \\
\hline Year 1 - wild-caught, mated at postpartum oestrus & 8 & $110-158$ & 133 & 16 & $133.5^{\mathrm{ij}}$ \\
\hline Year 2 - wild-caught, mated at regular oestrus & 29 & $113-169$ & 127 & 12 & $124^{\text {act }}$ \\
\hline Captive reared - damaged experiment & 21 & $113-141$ & 126 & 9 & $125.5^{\mathrm{bgh}}$ \\
\hline Captive reared - all animals* & 43 & $113-159$ & 119 & 9 & $116^{\text {cegil }}$ \\
\hline Captive reared - animals in 'normal' cages & 36 & $113-126$ & 117 & 3 & $116^{\mathrm{dfhjk}}$ \\
\hline Captive reared - animals in 'exceptional' cage & 7 & $115-159$ & 131 & 17 & $123^{\mathrm{kl}}$ \\
\hline
\end{tabular}

*Data are only for the animals in 'normal' and 'exceptional' cages; results of damaged experiment have been excluded.

${ }^{\text {abcdefgh }}$ Values with the same superscript are significantly different $(P<0.001)$.

${ }^{i j k}$ Values with the same superscript are significangly different $(P<0.01)$.

'Values with the same superscript are significantly different $(P<0.05)$.

21 females that were transferred to new groups during early pregnancy, 18 had gestation periods of 113-119 days, one had a gestation period of 124 days, and two gave birth to stillborn young or rejected their young immediately after birth. The median duration of gestation for females housed in one 'exceptional' cage (123 days) was significantly greater than that recorded for the animals in the remaining 'normal' cages (116 days) (Table 1). It is unclear whether this was due to the 
Table 2. Gestation periods for wild-caught short-tailed fruit bats, Carollia perspicillata, bred during their first and second years in captivity

\begin{tabular}{lll}
\hline & \multicolumn{2}{c}{ Gestation period (days) } \\
\cline { 2 - 3 } Animal & Year I & Year 2 \\
\hline 3 & $148^{*}$ & 169 \\
17 & $155^{*}$ & 114 \\
72 & 147 & 125 \\
Y-2 & 118 & 120 \\
Y-3 & $133^{*}$ & 116 \\
Y-8 & $110^{*}$ & 115 \\
\hline
\end{tabular}

*Bred at postpartum oestrus.

male used for mating in the 'exceptional' cage or to human disturbance. This cage was the closest to the animal room sink, and some activity associated with daily care of the bats was centered there (specifically, the cleaning and refilling of food dishes and water dispensers).

The median duration of gestation for females in the 'normal' cages was also significantly less than that for wild caught females bred in years 1 or 2 , or for captive reared females bred in the damaged experiment (Table 1).

Two captive reared animals that conceived at a postpartum oestrus and reared their young, while carrying the new pregnancy, had gestation periods of 115 and 116 days.

\section{Influence of male upon duration of gestation}

The possibility that male contributions to the fetal genome account for a significant portion of the observed variation in gestation period was considered. When pregnancies sired by each male are examined (Table 3), however, it is clear that the duration of gestation varied primarily with the history of the females. Considerable variation in gestation period was almost always seen whenever a male was mated with females in the following groups: (1) wild caught females, (2) captive reared females in the damaged experiment, or (3) captive reared females in the 'exceptional' cage. Less variation in duration of gestation was seen whenever a male was bred with captive reared females in the 'normal' cages. Of particular interest are the pregnancies sired by male LB-13. Broad variation in gestation period was noted when this male mated with wild caught females or captive reared females in the damaged experiment. Little variation was found when the same male mated with captive reared females in the 'normal' cages.

\section{Condition of animals examined during pregnancy}

When animals were killed at daily intervals commencing on day 12 after mating and subjected to histological analysis, the first clear evidence of implantation (that is, trophoblastic penetration of the uterine epithelium) was observed in some animals on day 13 after mating (Table 4). It should be cautioned that the detection of earlier phases of the implantation process was probably interfered with by shrinkage of the specimens during histological processing. Implantation had been completed (that is, the first endometrial capillaries had been engulfed by trophoblast) in one of five pregnant females examined on day 17 after mating and four of five pregnant females examined on day 18 after mating (Fig. 2).

Histological examination of gravid reproductive tracts during and after implantation often revealed some developmental variation between embryos obtained on the same day after mating (Badwaik et al., in press). Primitive streak development and the formation of mesoderm was seen in one of four embryos on day 23 , none of five on day 24 , one of five on day 25 , two of three on day 26 , and two of two on day 28 after mating. Thereafter, some embryos remained at the primitive streak stage, while development progressed in others (Table 5). For example, Figs 3 and 4 show embryos carried by two different females on day 50 after mating. Although the development of many embryos was clearly delayed at the primitive streak stage, mitotic activity continued to be evident in both the epiblast of the embryonic shield and the cytotrophoblast of the preplacenta in all such embryos.

As pregnancy progressed, considerable variation was also seen in the maximum diameter of the uterus and the size of the conceptus at the same or similar time intervals after mating (Figs 5-7). Uterine diameter and the stage or size of conceptus development were often greater in animals mated during years 2 and 3 , compared with those mated in year 1 ; however, there were exceptions to this pattern.

\section{Minimum gestation periods for pregnant, wild caught bats}

During November 1991 and October 1993 female Carollia were collected in the wild and then maintained in all-female groupings for at least 3-4 months. Many females in the November 1991 group gave birth at 129-181 days after being isolated initially in sexually segregated groupings in captivity (Fig. 8). Although some of these females were housed with males during late pregnancy, the pregnancies were known to be the result of inseminations that had occurred in the wild. Many females in the October 1993 group gave birth at 116-229 days after being sexually isolated from the time of their arrival in New York (Fig. 9). All of these females were assumed to have been pregnant or recently inseminated at the time of capture for the following reasons: (1) no evidence of prolonged sperm storage has been observed when the reproductive tracts of captive bred Carollia were examined histologically in this study or a previous one (Bonilla and Rasweiler, 1974; Rasweiler and Bonilla, 1991; Badwaik et al., in press); (2) one female captured on October 21, 1993 had a vaginal plug; and (3) most females (19 of 20) collected in the same area on November 9, 1995 were in early pregnancy (Table 6).

An approximate, minimal age for these embryos is provided in Table 6 by including the earliest day after mating on which comparable stages were observed in captive bred animals. A potential shortcoming of this approach is that the development of some embryos in the captive bred bats may have been delayed. This should have been minimized, however, by the fact that: (1) between days 12 and 34 after mating most of the embryos studied ( $n=65$ of 79 ) were carried by females mated 
Table 3. Duration of pregnancies sired by different male short-tailed fruit bats, Carollia perspicillata

\begin{tabular}{|c|c|c|c|c|c|c|}
\hline \multirow{2}{*}{$\begin{array}{l}\text { Male } \\
\text { number }\end{array}$} & \multirow[b]{2}{*}{ History of pregnant females } & \multirow{2}{*}{$\begin{array}{l}\text { Number of } \\
\text { pregnancies }\end{array}$} & \multicolumn{4}{|c|}{ Duration of gestation (days) } \\
\hline & & & Range & Mean & SD & Median \\
\hline \multirow[t]{3}{*}{ LB 1} & Year 1 - wild-caught, bred at regular oestrus & 2 & $113-155$ & 134 & 30 & $134^{\mathrm{a}}$ \\
\hline & Year I - wild-caught, bred at postpartum oestrus & 3 & $140-158$ & 149 & 9 & $148^{\mathrm{b}}$ \\
\hline & Year 2 - wild-caught, bred at regular oestrus & 5 & $114-169$ & 129 & 23 & $119^{c}$ \\
\hline & Captive reared, in 'normal' cages & 10 & $113-119$ & 117 & 4 & $116.5^{\mathrm{eyz}}$ \\
\hline \multirow[t]{3}{*}{ LB 16} & Year 1 - wild-caught, bred at regular oestrus & 1 & 164 & 164 & - & 164 \\
\hline & Year 1 - wild-caught, bred at postpartum oestrus & 4 & $112-134$ & 124 & 12 & $125.5^{\mathrm{b}}$ \\
\hline & Year 2 - wild-caught, bred at regular oestrus & 8 & $114-138$ & 126 & 7 & $124.5^{\mathrm{c}}$ \\
\hline \multirow[t]{2}{*}{ LB 17} & Year 2 - wild-caught, bred at regular oestrus & 16 & $113-145$ & 127 & 11 & $125.5^{\mathrm{c}}$ \\
\hline & Captive bred, damaged experiment & 6 & $120-141$ & 131 & 8 & $131.5^{\mathrm{d}}$ \\
\hline LB 3 & Captive reared, in 'normal' cages & 11 & $113-126$ & 116 & 4 & $115^{e}$ \\
\hline LB 21 & Captive reared, in 'normal' cages & 7 & $113-124$ & 115 & 4 & $114^{e}$ \\
\hline LB 9 & Captive reared, in 'exceptional' cage & 7 & $115--159$ & 131 & 17 & 123 \\
\hline
\end{tabular}

Because of their limited value, data for males that sired only one or two pregnancies have not been included.

abcde Common superscript indicates that values for females treated similarly, but mated with different males, are not significantly different.

${ }^{x y z}$ Common superscript indicates that values for females in the two treatment groups were significantly different $(P<0.02)$.

Table 4. Reproductive status of captive bred short-tailed fruit bats, Carollia perspicillata, at daily intervals during the peri-implantation period of pregnancy

Day after mating on which stages were observed

\begin{tabular}{|c|c|c|c|c|c|c|c|c|c|c|c|}
\hline \multirow[b]{2}{*}{ Embryonic stage and location } & & & & & & & & & & & \\
\hline & 10 & 11 & 12 & 13 & 14 & 15 & 16 & 17 & 18 & 19 & 20 \\
\hline Oviductal morula & 2 & - & - & - & - & - & - & - & - & - & - \\
\hline Oviductal blastocyst $(-\mathrm{ZP})$ & - & 2 & 1 & - & $1^{*+}$ & - & $1^{*}$ & - & - & - & - \\
\hline $\begin{array}{l}\text { Uterine blastocyst (close to uterotubal junction/outside } \\
\text { implantation zone) }\end{array}$ & - & - & 1 & 1 & - & - & - & - & - & - & - \\
\hline Implanted uterine blastocyst & - & - & - & - & - & - & - & 1 & $4^{\dagger}$ & $4^{\dagger}$ & $6^{\dagger}$ \\
\hline
\end{tabular}

Table indicates number of females carrying an embryo at that stage and location on each day. Each female carried a single blastocyst.

+ ZP: blastocyst still surrounded by zona pellucida; - ZP: blastocyst had shed zona pellucida; *abnormally small blastocyst.

${ }^{\dagger}$ Includes one female mated during her first year in captivity; ${ }^{+}$includes two females mated during their first year in captivity.

during their second or third year in captivity; (2) prolonged pregnancies were seen less frequently in second year animals (Fig. Ia,b); and (3) the most rapidly developing embryos in the captive bred bats were always used for the comparisons.

\section{Timing of parturition in the wild population}

The same colony of Carollia that provided the data in Table 6 was visited on 19 April 1994 and 24 April 1995. On both occasions many females were observed with suckling young. Twenty adult females were collected randomly from that colony on 1 April 1996, and these carried the fetuses or suckling young with the body masses shown (Fig. 10). Figure 10 also shows the masses recorded for 12 infants on their day of birth in the captive colony. Body masses recorded for five fetuses obtained from females in the captive colony on days 110-118 after mating are included in Fig. 7. On the basis of their mass (4.85-5.96 g) and well-furred dorsal body surfaces, it seems likely that these fetuses were very close to being delivered. 


\section{Discussion}
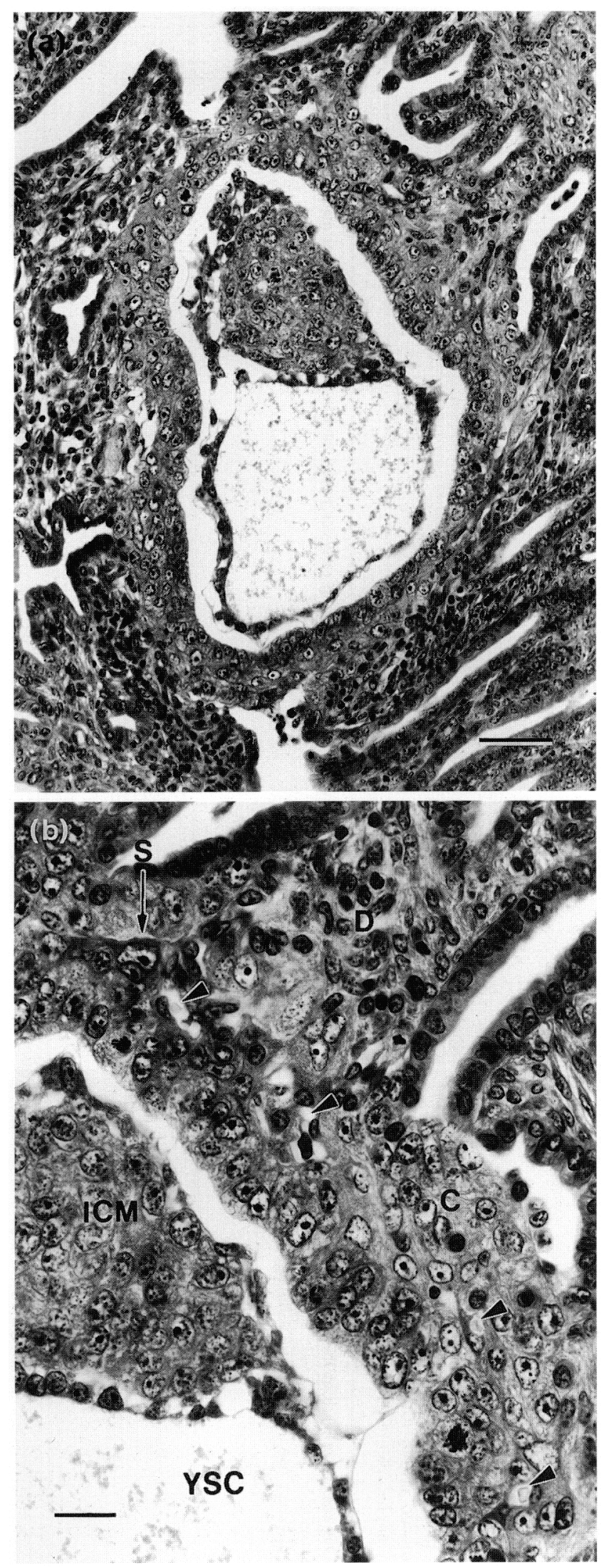

In previous work with captive C. perspicillata some females exhibited interbirth intervals of as little as 105-125 days (Kleiman and Davis, 1979; Laska, 1990). The gestation periods would presumably have been shorter for these animals, because the postpartum oestrus in most Carollia does not commence until at least 3-6 days after parturition (Rasweiler and Badwaik, 1996). Laska (1990) reported the shortest intervals (105 and 108 days). He did not indicate whether the young were successfully reared (which would imply that the deliveries were not significantly premature), but noted that infant mortality in his colony was high. In the present study two young were reared after gestation periods of 105 and 110 days. In both of the earlier studies, significantly longer interbirth intervals were also frequently observed, but their relationship to actual gestation periods was not determined.

Most of the gestation periods recorded for wild caught animals mated during their first year in captivity were well over 120 days and must have included a significant period of retarded conceptus development. The histological studies of tracts obtained during early pregnancy indicate that much, if not all, of the delay occurs after the initiation of implantation. That is because by day 19 after mating all embryos were implanted. It is difficult to identify, however, exactly when the delay begins and ends. Developmental differences have been noted between embryos obtained on the same day after mating, during the implantation period (N. K. Badwaik, S. F. Oliveira and J. J. Rasweiler IV, unpublished); however, the extent to which this is due to variation in the time of conception or embryo transport into the uterus, as opposed to retarded embryonic development, is unclear. Studies of postimplantation embryos revealed that there was at least a difference of 3 days between the earliest and latest appearance of a primitive streak and the formation of mesoderm (Badwaik et al., in press). Furthermore, development was clearly retarded in many embryos at the primitive streak stage. Twelve embryos examined between day 38 and day 60 after mating were still at this stage, while two somite stage embryos were observed as early as day 36 after mating. The extent to which retarded development continues after the primitive streak stage requires further study of conceptus development in normal versus delayed pregnancies.

Although development was retarded in many of the embryos, there was no evidence that it had stopped in any of those subjected to histological analysis. All of the implanting and postimplantation embryos examined (N.K. Badwaik and J. J. Rasweiler IV, unpublished), including those at the primitive streak stage, exhibited mitotic activity in both the epiblast and

Fig. 2. (a) Just implanted blastocyst of a short-tailed fruit bat, Corollio perspicillata on day 18 after mating. (b) Higher power view of a portion of this blastocyst. By this stage some of the first endometrial capillaries (arrowheads) had been engulfed by trophoblast. Most of this is cytotrophoblast (C), but some darker staining syncytiotrophoblast (S) has begun to differentiate around the engulfed capillaries, particularly at the embryonic pole. D: decidua. ICM: inner cell mass YSC: yolk sac cavity. Staining was by Masson's trichrome procedure. Scale bars represent $50 \mu \mathrm{m}(\mathrm{a})$ and $20 \mu \mathrm{m}$ (b). 


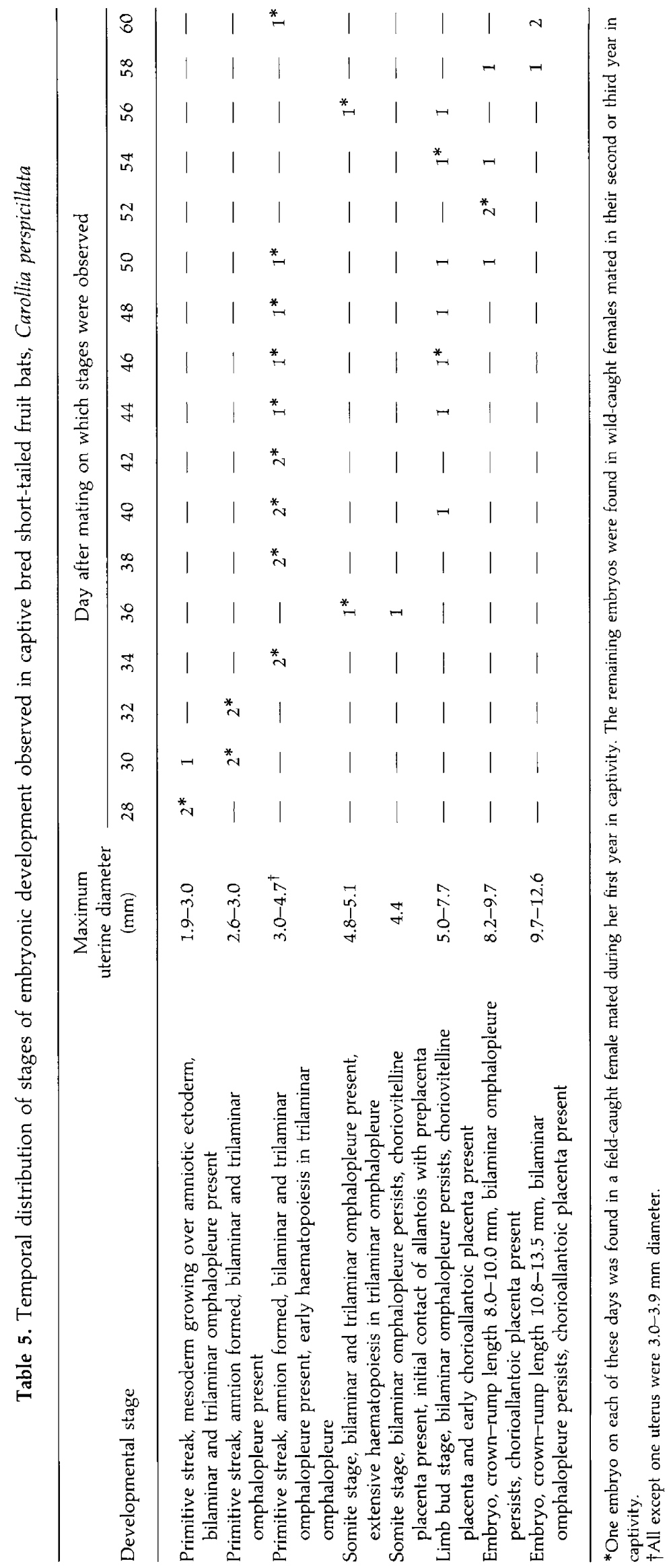

Downloaded from Bioscientifica.com at 04/26/2023 12:47:33AM 


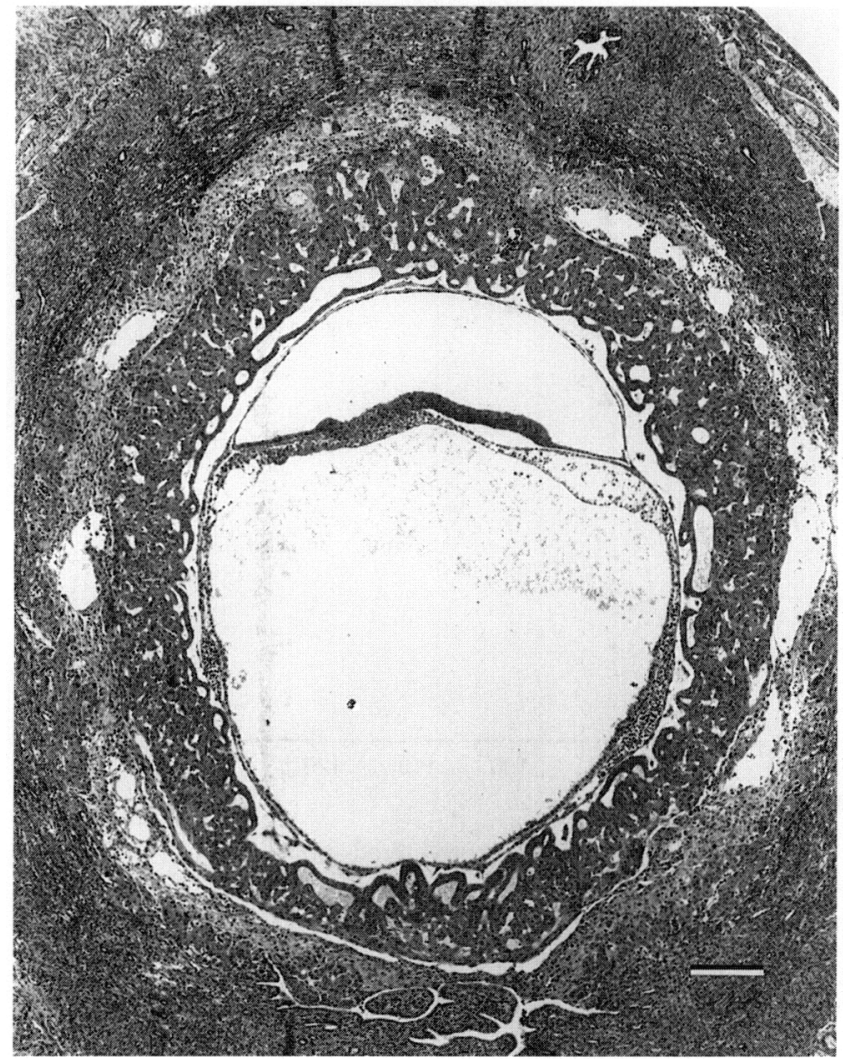

Fig. 3. Primitive streak stage embryo found in a female short-tailed fruit bat, Carollia perspicillata on day 50 after mating. Staining was with PAS-haematoxylin. Scale bar represents $200 \mu \mathrm{m}$.

cytotrophoblast. In this respect delayed development in captive Carollia resembles that described for two other phyllostomid bats, Macrotus waterhousii californicus and Artibeus jamaicensis in the wild (Bradshaw, 1962; Fleming, 1971; Bleier, 1975). In Macrotus and Artibeus, growth of the embryo also continues during the delay, albeit at a retarded rate, and then accelerates. In these two species, much of the delay occurs before the primitive streak stage, whereas in Carollia this stage is clearly extended.

When delayed development was observed initially in some Carollia mated during their first year in captivity, two hypotheses were formulated to account for its occurrence: (1) the phenomenon may somehow be related to the age or parity of the females; or (2) it may be induced by stress associated with captivity. The first hypothesis was proved untenable because delayed development was found to be less pronounced (although not completely eliminated) in both younger, nonparous, captive reared females and older, wild caught females mated during their second year in captivity. It seems reasonable to propose that such animals would be less stressed by confinement, as well as human activity related to their husbandry, than recently captured bats.

The husbandry methods used in this work permit the introduction of Carollia into captivity with very low mortality rates (the 6 month survival rate of animals from the time of capture on the last two collecting trips was 72 of $76(94.7 \%)$ and 60 of $60(100 \%)$; J. J. Rasweiler IV and N. K. Badwaik, unpublished) and are conducive to the successful breeding of

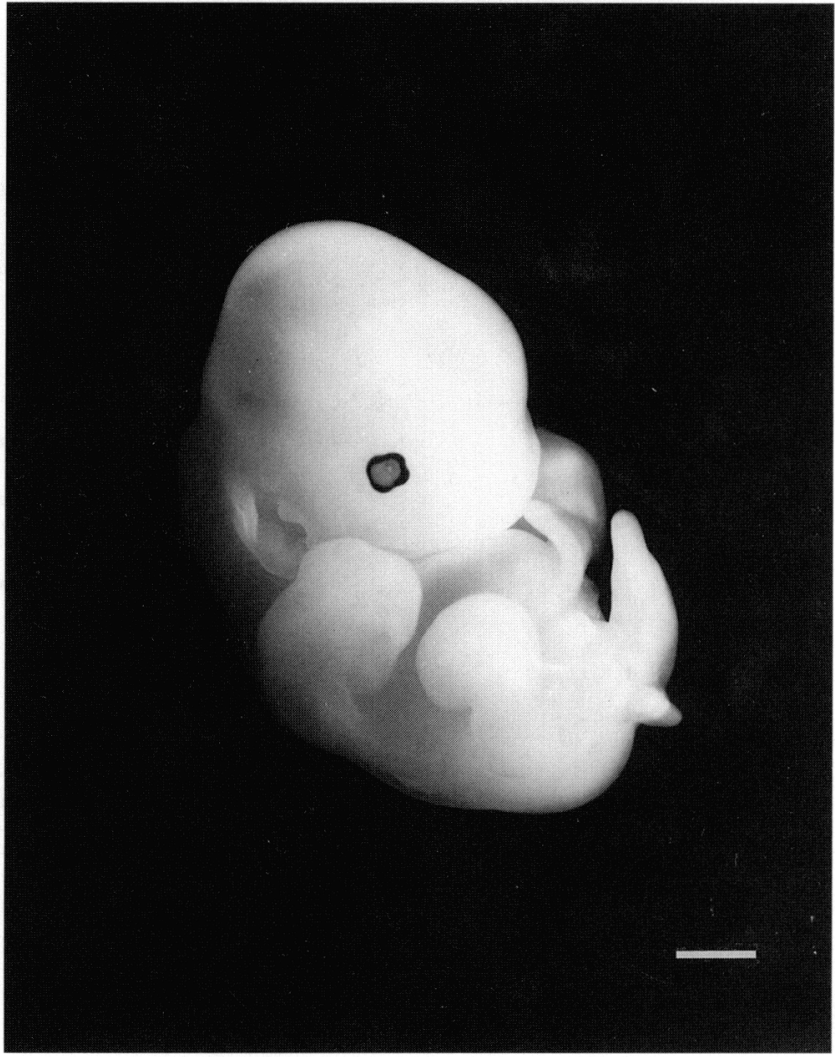

Fig. 4. Short-tailed fruit bat, Carollia perspicillata embryo at the limb plate stage ( $8.3 \mathrm{~mm}$ crown-rump length) found in a female on day 50 after mating. Scale bar represents $1 \mathrm{~mm}$.

the bats. However, breeding performance was poorer during the animals' first year of captivity. In addition, housing females that were pregnant from the wild with stud males and handling such females on a daily basis frequently resulted in abortions or the rejection of newborn young. There is evidence that both this poor breeding performance, and the loss of pregnancies or newborn young, may have been due to stress (Rasweiler and Badwaik, 1996). A high initial rate of reproductive failures has also been observed after the introduction of other wild species into captivity (Rasweiler, 1977), and stress was found to have a pronounced effect upon glucocorticoid secretion in some captive bats (Widmaier and Kunz, 1993; Widmaier et al., 1994).

The variability in duration of gestation exhibited by captive bred Carollia was reduced by waiting for at least a year before breeding wild caught animals and much more so by breeding females reared in captivity. If the longer gestation periods associated with one particular cage and an experiment damaged by problems with the animal room environment are ignored, most captive born and bred bats had gestation periods of 113-119 days. This may represent the "normal' (nondelayed) gestation period for this species. Results obtained in the damaged experiment and from the 'exceptional' cage indicate that the duration of gestation in captive reared Carollia is also subject to serious perturbation under some circumstances.

The extremely long minimum gestation periods (150-229 days) observed in some Carollia that were probably pregnant when captured indicates that the maximum retardation of 


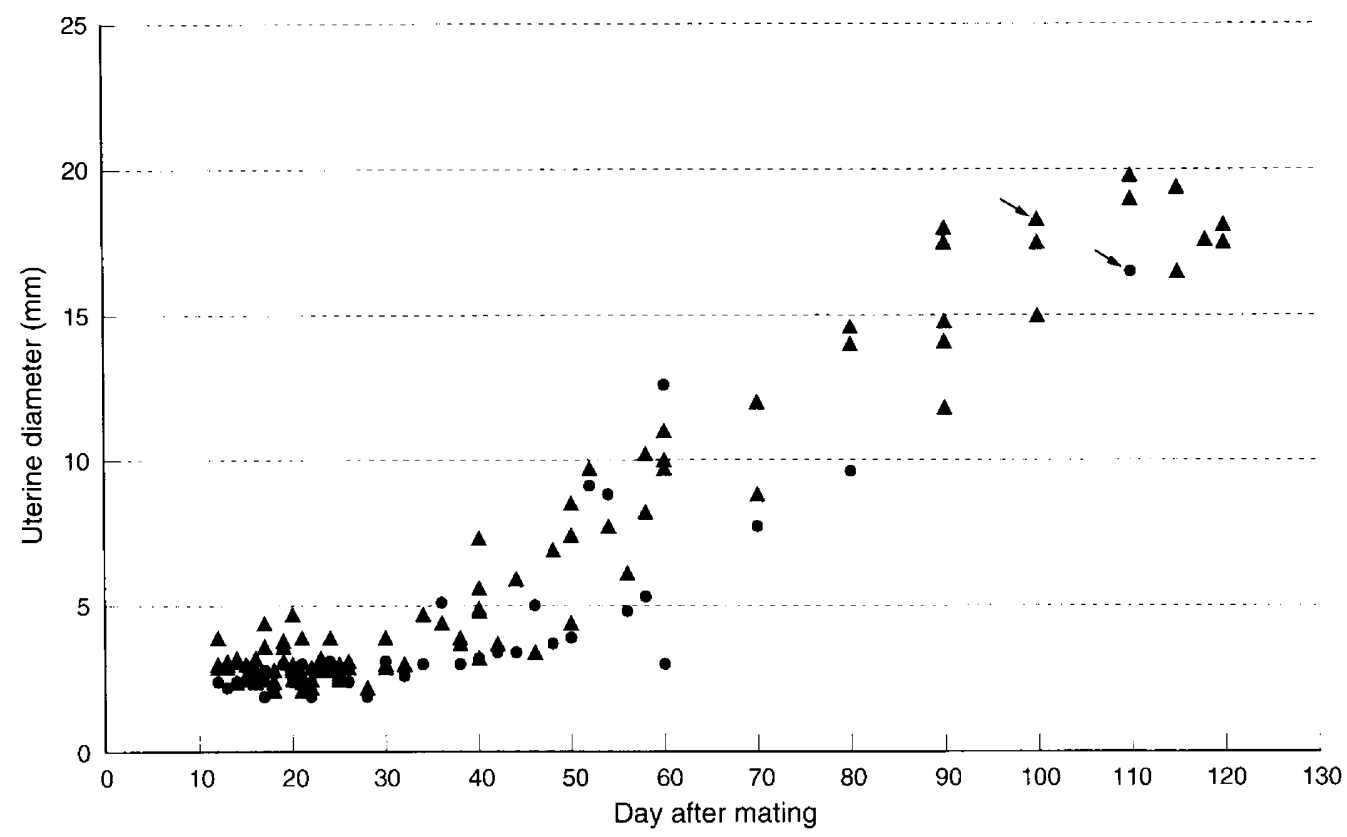

Fig. 5. Maximum diameter (transverse dimension) of the simplex uterus in pregnant, captive bred short-tailed fruit bats, Carollia perspicillata. (•) Female mated during her first year in captivity. (^) Female mated during her second or third year in captivity. Each arrow indicates that two uteri had the same diameter.

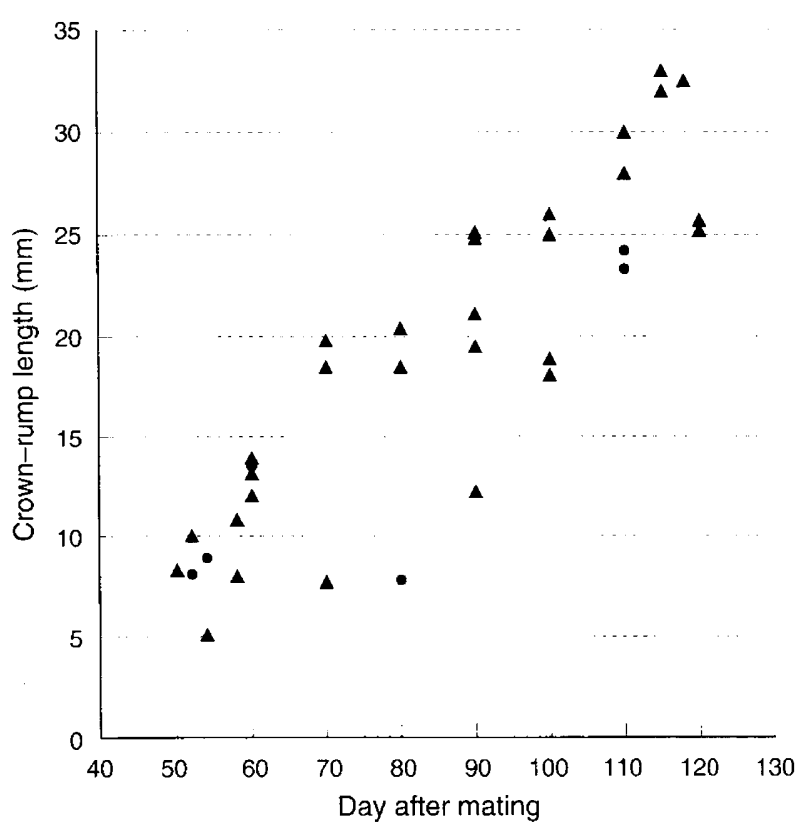

Fig. 6. Fetal crown-rump lengths in captive bred short-tailed fruit bats, Carollia perspicillata. (•) Female mated during her first year in captivity. ( $\mathbf{\Delta}$ ) Female mated during her second or third year in captivity.

embryonic development was not observed in captive bred animals. Although this suggests initially that the stress of being introduced into captivity could have a particularly strong effect upon the progression of pregnancy, that may or may not be the case. Studies of the wild population clearly indicate that the pregnancies in progress during October and November include some retardation of development (see below). That being the

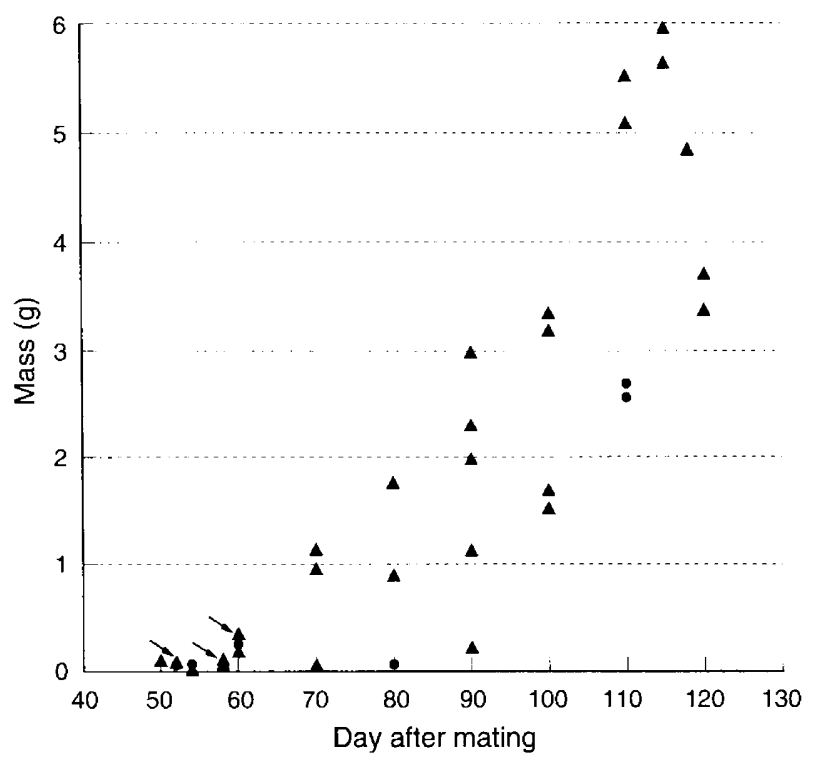

Fig. 7. Conceptus masses for captive bred short-tailed fruit bats, Carollia perspicillata. (•) Female mated during her first year in captivity. (ム) Female mated during her second or third year in captivity. Each arrow indicates that two conceptuses had similar mass.

case, some of the prolongation of pregnancy observed in the animals introduced into captivity may have been due to seasonal factors rather than stress.

Some of the evidence for the existence of retarded development in the wild population, and an estimate of its minimum effect upon duration of gestation, are outlined (Table 7). The time of conception for most of the pregnant females captured in November 1995 was estimated by using temporal data for the most rapidly developing embryos in captive bred bats. The 


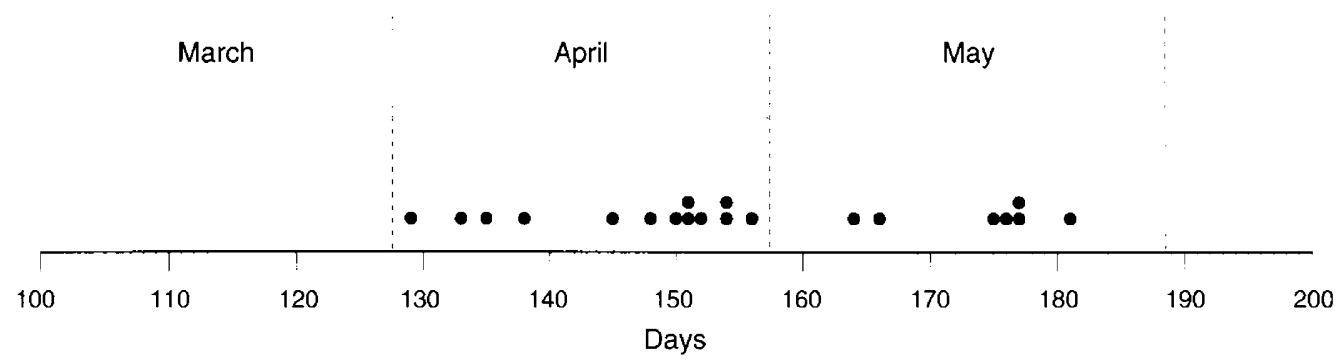

Fig. 8. Minimum possible gestation periods for pregnant, wild caught short-tailed fruit bałs, Carollia perspicillata sexually isolated in captivity on 26 November 1991. (•) Indicates date on which newborn offspring was found.

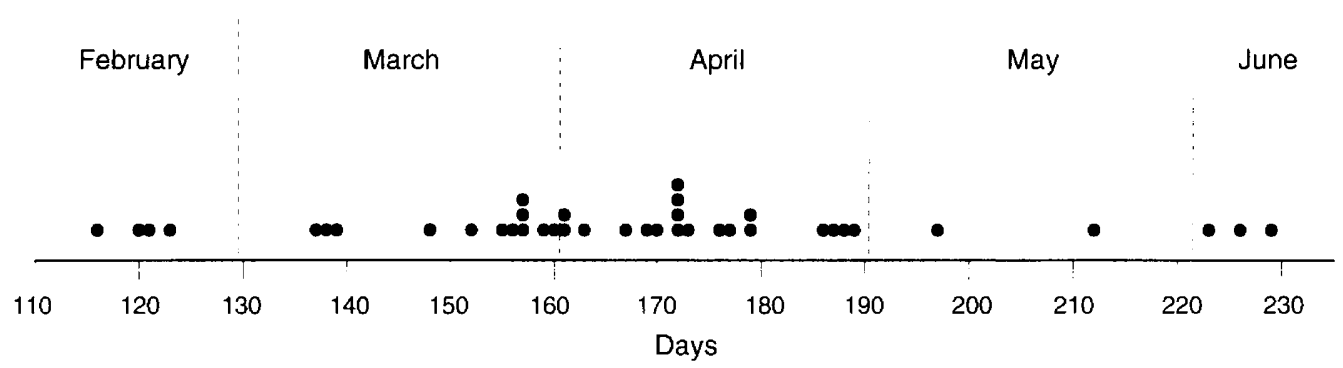

Fig. 9. Minimum possible gestation periods for pregnant, wild caught short-tailed fruit bats, Carollia perspicillata, sexually isolated in captivity on 23 October 1993. (•) Indicates date on which newborn offspring was found.

Table 6. Reproductive condition of female short-tailed fruit bats, Carollia perspicillata, collected on Trinidad, West Indies on 9 November 1995

Number

of bats
Earliest day after mating on which comparable stage has been observed in captive bred bat*

Nonpregnant, growing vesicular follicles, early preovulatory oviductal stimulation

Pronuclear stage ovum, regressing corpus luteum, menstrual uterus

Oviductal morula (53 cells)

Implanting blastocyst, trophoblast penetration to uterine epithelial basal lamina, reticulated endoderm or small, unilocular yolk sac

Implanting blastocyst, early trophoblast penetration of endometrial stroma, unilocular yolk sac

Implanted blastocyst, elongation and similar orientation of some epiblast cells in the inner cell mass, large unilocular yolk sac

Implanted blastocyst, extensive apoptosis and multiple cavities within the epiblast (amniogenesis in progress)

Implanted blastocyst, large primordial amniotic cavity formed, bilaminar omphalopleure only

Primitive streak, mesoderm growing over amniotic ectoderm, bilaminar and trilaminar omphalopleure present

Primitive streak, amnion formed, bilaminar and trilaminar omphalopleure present

Primitive streak, amnion formed, bilaminar and trilaminar present, early haematopoiesis in trilaminar omphalopleure

*These comparisons are based in part upon observations presented in Bonilla and Rasweiler (1974) and Badwaik et al. (in press). The implanting and postimplantation embryos were all found in females that were mated during their second or third year in captivity.

time of parturition for the females captured in April 1996 was estimated by comparing the size of their fetuses and suckling young with: (1) fetuses or day of birth of young in the captive colony; and (2) a postnatal growth curve for captive born C. perspicillata of Trinidadian descent (Kleiman and Davis, 1979). As is evident from one bat carrying a pronuclear stage ovum on 9 November, some females can be thrown out of synchrony with the rest of the population when they suffer a reproductive failure, run a nonpregnant cycle, and then ovulate again. The omission of females carrying laggard embryos and fetuses has only a minimal effect upon the estimated duration of the delay in the wild (Table 7). The estimated interval 


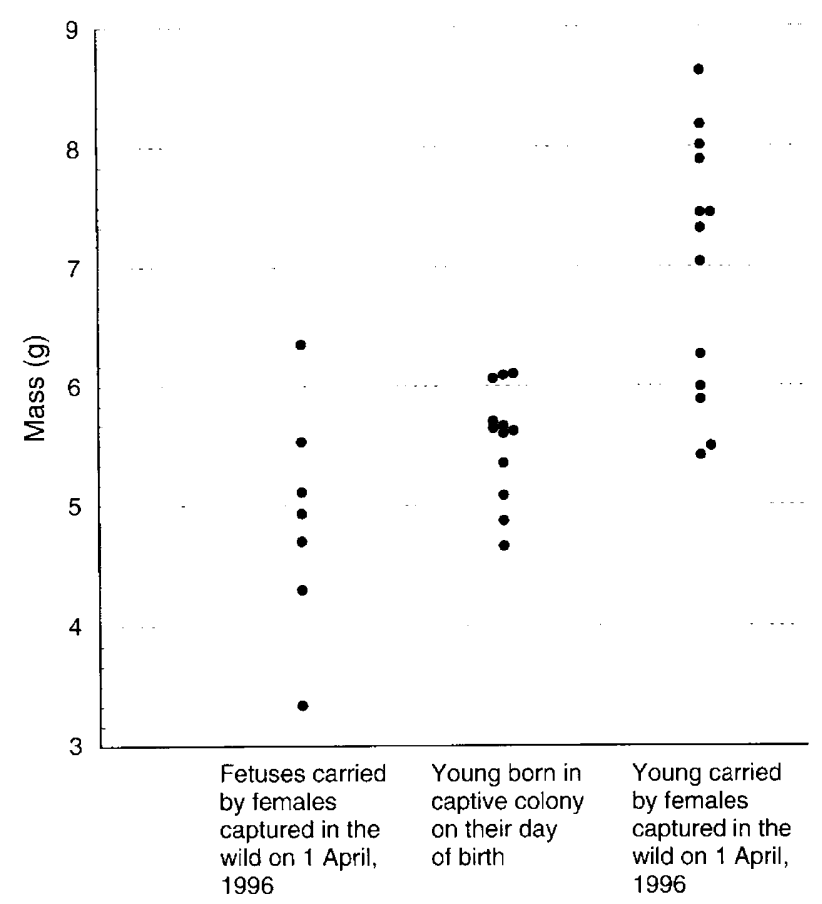

Fig. 10. Masses of fetuses and recently born young collected in the wild compared with the masses of captive born young short-tailed fruit bats, Carollia perspicillata, on their day of birth.

between the breeding and parturition periods with either method is such that the females could only have carried one pregnancy to term during this time.

In view of the early stages of development of the embryos collected in November, the methodology used to estimate their time of conception seems unlikely to result in a serious overestimate of the extent to which pregnancy is retarded in the wild. However, there are reasons to be concerned that it may underestimate the extent of the delay, because the growth of some of the embryos collected in November may have already slowed. All of the wild females carrying advanced primitive streak stage embryos at this time exhibited a highly unusual and pronounced invasion of the myometrium by perivascular cytotrophoblast. A similar invasion has been noted in captive bred females with pregnancies in delay, while this invasion is much less pronounced in apparently normal or slightly delayed pregnancies (J. J. Rasweiler and N. K. Badwaik, unpublished). Furthermore, some of the females giving birth during March and April apparently have a postpartum oestrus. Deoraj (1987) captured Trinidadian Carollia carrying suckling young and oviductal or early uterine embryos on 16 April and large fetuses ( $16-25 \mathrm{~mm}$ crown-rump length) on 17 July. In the captive colony most Carollia come into oestrus again within 3-6 days after parturition (Rasweiler and Badwaik, 1996) and can produce an offspring within 120 days of the commencement of breeding activity (if the pregnancy is not retarded). Therefore, a conservative estimate of the minimum time required to have a postpartum oestrus after each birth and to produce offspring is 132 days. Yet the interval from the estimated middle of the March-April birth period to the estimated middle of the October breeding period is 204 days. This raises the possibility that: (1) the pregnancies in progress in July also may be retarded; (2) the females may not experience a postpartum oestrus immediately after these pregnancies; or (3) the next breeding period may occur earlier than October and be followed by a longer period of retarded development. Cosson and Pascal (1994) have used similar reasoning to postulate that a reproductively synchronized population of C. perspicillata in French Guiana may exhibit a period of retarded embryonic development during the long interval (about 7 months) between their rainy season and dry season birth periods.

Although it is well known that delayed implantation occurs during lactation in some marsupials, insectivores and rodents that exhibit a postpartum oestrus (Renfree and Calaby, 1981; Mead, 1993), no evidence was obtained that lactation induces embryonic diapause in Carollia. Pregnancies established at a postpartum oestrus in two captive reared animals were 115 and 116 days long. This does not seem unreasonable, because even in the most rapidly progressing pregnancies in Carollia, early development of the embryo is slow and there is no detectable swelling of the uterus at the end of the first month.

There would appear to be two situations in which having the ability to retard pregnancies in response to stress could be of considerable value to Carollia. One would be if unusual climatic conditions (for example, severe weather) suddenly reduce the food supply during the reproductive season, that is, after pregnancies have been established. A study by Gannon and Willig (1994) provides evidence that a severe hurricane seriously affected reproductive activities in other phyllostomid bats on Puerto Rico. The ability to slow pregnancies in response to stress may also be of value if pregnant Carollia are

Table 7. Temporal evidence for the existence of delayed embryonic development in a wild population of short-tailed fruit bats, Carollia perspicillata, on the island of Trinidad, West Indies

\footnotetext{
Estimated time of conception for females carrying embryos on 9 November 1995 Estimated time of parturition for females carrying suckling young or fetuses on 1 April 1996

Interval between the middle of the estimated conception period and the middle of the estimated parturition period

Normal (nondelayed) gestation period for captive bred females

Estimated minimum delay in the wild
}
6 October-7 November ${ }^{\dagger}$
II March-22 April
163 days
113-119 days
$44-50$ days $^{\dagger}$

Exclusion of the pronuclear stage ovum and the two least developed fetuses changes the estimated interval between the middle of the breeding and parturition periods to 158 days, and the estimated minimum delay to $39-45$ days. ${ }^{\dagger}$

${ }^{t}$ Estimates assume that the embryos found on 9 November were not already in delay. 
forced to abandon a roost. On a number of occasions, sizeable Carollia colonies on Trinidad have had to relocate when humans reoccupied unused buildings that were being used by the bats as diurnal roosts (J. J. Rasweiler IV and N. K. Badwaik, unpublished). Many of the displaced animals presumably had to compete for space in other occupied roosts or to relocate to less desirable roosts. In the latter sites heavily gravid or lactating females, or newborn young, could be more exposed to predation and environmental extremes. One can envision natural phenomena (for example, the loss of hollow trees or cave roosts) that would have similar consequences. The preservation of existing pregnancies, when faced by such difficulties, would be especially important to Carollia, because this species normally produces only a single young after a long gestation period. Furthermore, previous studies indicate that Carollia has two breeding seasons per year in the wild (Willig, 1985; Fleming, 1988; Cosson and Pascal, 1994). Resorptions of early pregnancies, abortions, or the rejection of newborns would seem to be more acceptable strategies to cope with severe stress for species (for example, murid rodents) that can produce sizeable litters after short gestation periods (see Sadlier, 1969; Christian, 1971).

While there is now evidence that delayed development occurs both in response to stress in captive Carollia and seasonally in the wild population, its physiological control remains obscure. Two possibilities would seem to exist: (1) control of the phenomenon may differ in the two situations, although presumably some common final pathways would still be involved; or (2) the phenomenon in the wild may be triggered by stress as well, but of a seasonally recurring nature. The possibility that diapause can be induced both seasonally and by stress in the same species means that considerable care must be exercised in the design and interpretation of experiments seeking to elucidate underlying physiological mechanisms. This raises concern that previous efforts to alter the seasonal period of delayed development in the closely related Macrotus californicus (Burns et al., 1972; Burns, 1981) may have been affected by the stress of introducing the animals into captivity.

Finally, it is interesting to note that major stress (for example, being introduced into captivity and, in some cases, shipped to another laboratory) can greatly lengthen pregnancy in the nine-banded armadillo, Dasypus noverncinctus (Storrs et al., 1988). Although this species is known to exhibit delayed implantation (Enders, 1966), some of the females showing a stress-induced prolongation of gestation had been captured and sexually isolated after the presumed time of implantation. This suggests that both pre- and postimplantation development may be delayed under such circumstances (Storrs et al., 1988). The observation of such profound effects of stress upon duration of gestation in representatives of two different mammalian orders (the Chiroptera and the Xenarthra) raises the question of its possible occurrence in other orders.

The authors are grateful to Y. Chvojka, A. Piccolie, A. O'Neill and S. Williams for technical assistance. Thanks also go to the staff of the Department of Zoology of the University of the West Indies, St Augustine, Trinidad for their generous help and the use of department facilities during the field work required for this study. This research has been supported by the Department of Obstetrics and
Gynecology, Cornell University and National Institutes of Health Grant HD-28592. Finally, thanks are due to the United States Educational Foundation in India and the Council for International Exchange of Scholars for their support and assistance to N. K. Badwaik as a Visiting Scholar under the Fulbright Scholar Program.

\section{References}

Bernard RTF and Meester JAJ (1982) Female reproduction and the female reproductive cycle of Hipposideros caffer caffer (Sundevaal, 1846) in Natal, South Africa Annals of the Transvaal Museum 33 131-144

Badwaik NK, Rasweiler JJ, IV and Oliveira, SF Formation of reticulated endoderm, Reichert's membrane, and amniogenesis in blastocysts of captive-bred, short-tailed fruit bats, Carollia perspicillata. Anatomical Record (in press)

Bhiwgade DA (1979) An analysis of implantation in Indian hipposiderid bats Journal of Anatomy 128 349-364

Bleier WJ (1975) Early embryology and implantation in the California leaf-nosed bat, Macrotus californicus. Anatomical Record 182 237-254

Bodley HD (1974) Ultrastructural development of the chorioallantoic placental barrier in the bat Macrotus waterhousii. Anatomical Record $180351-368$

Bonilla H de and Rasweiler, JJ, IV (1974) Breeding activity, preimplantation development, and oviduct histology of the short-tailed fruit bat, Carollia, in captivity Anatomical Record 179 385-404

Bradshaw GVR (1962) Reproductive cycle of the California leaf-nosed bat, Macrotus californicus. Science $136645-646$

Burns JM (1981) Aspects of endocrine control of delay phenomena in bats with special emphasis on delayed development Journal of Reproduction and Fertility Supplement 29 61-66

Burns JM, Baker RJ and Bleier WJ (1972) Hormonal control of 'delayed development' in Macrotus waterhousii. I. Changes in plasma thyroxine during pregnancy and lactation General and Comparative Endocrinology $1854-58$

Christian JJ (1971) Population density and reproductive efficiency Biology of Reproduction 4 248-294

Clifford C and Taylor KB (1973) A useful variant of the Movat pentachrome I stain Stain Technology 48 151-152

Cosson JF and Pascal M (1994) Strategie de reproduction de Carollia perspicillata (L., 1758) (Chiroptera, Phyllostomidae) en Guyane Francaise Revue d'Ecologie (la Terre et la Vie) $\mathbf{4 9} \quad 117-137$

Crichton EG, Seamark RF and Krutzsch PH (1989) The status of the corpus luteum during pregnancy in Miniopterus schreibersii (Chiroptera: Vespertilionidae) with emphasis on its role in developmental delay Cell and Tissue Research 258 183-201

Deoraj P (1987) The Reproductive Biology of the Neotropical Bats Carollia perspicillata, Anoura geoffroyi and Natalus tumidirostris. MPhil Thesis, The University of the West Indies, St Augustine

Enders AC (1966) The reproductive cycle of the nine-banded armadillo (Dasypus novemcinctus). In Comparative Biology of Reproduction in Mammals pp 295-310 Ed. IW Rowlands. Academic Press Inc, London

Fleming TH (1971) Artibeus jamaicensis: delayed embryonic development in a neotropical bat Science 171 402-404.

Fleming TH (1988) The Short-tailed Fruit Bat University of Chicago Press, Chicago

Gannon MR and Willig MR (1994) The effects of Hurricane Hugo on bats of the Luquillo Experimental Forest of Puerto Rico Biotropica 26 320-331

Heideman PD (1989) Delayed development in Fischer's pygmy fruit bat, Haplonycteris fischeri, in the Philippines Journal of Reproduction and Fertility 85 363-382

Humason GL (1972) Animal Tissue Technic and Practical Histochemistry The Blakiston Division, McGraw-Hill Book Company, New York

Kimura K and Uchida TA (1983) Ultrastructural observations of delayed implantation in the Japanese long-fingered bat, Miniopterus schreibersii. fuliginosus. Journal of Reproduction and Fertility 69 187-193

Kleiman DG and Davis TM (1979) Ontogeny and maternal care. In Biology of Bats of the New World Family Phyllostomatidae, Part III pp 387-402 Eds RJ Baker, JK Jones, Jr and DC Carter. Texas Tech Press, Lubbock, TX

Krishna A and Dominic CJ (1982) Differential rates of fetal growth in two successive pregnancies in the emballonurid bat, Taphozous longimanus Hardwicke Biology of Reproduction 27 351-353

Laska M (1990) Gestation period and between-birth intervals in Carollia perspicillata (Phyllostomatidae, Chiroptera) Journal of Zoology, London $\mathbf{2 2 2}$ 697-702 
Mead RA (1993) Embryonic diapause in vertebrates Journal of Experimental Zoology 266 629-641

Mitchell GC (1965) A Natural History Study of the Funnel-eared Bat, Natalus stramineus. MSc Thesis. University of Arizona, Tucson

Racey PA (1969) Diagnosis of pregnancy and experimental extension of gestation in the pipistrelle bat, Pipistrellus pipistrellus. Journal of Reproduction and Fertility $19465-474$

Racey PA and Swift SM (1981) Variation in gestation length in a colony of pipistrelle bats (Pipistrellus pipistrellus) from year to year Journal of Reproduction and Fertility 61 123-129

Rasweiler JJ, IV (1977) The care and management of bats as laboratory animals. In The Biology of Bats, Vol. III pp 519-617 Ed. WA Wimsatt. Academic Press Inc., New York

Rasweiler JJ, IV and Badwaik NK (1996) Improved procedures for maintaining and breeding the short-tailed fruit bat (Carollia perspicillata) in a laboratory setting Laboratory Animals 30 171-181

Rasweiler JJ, IV and Bonilla H de (1991) Menstruation in short-tailed fruit bats (Carollia spp.) Journal of Reproduction and Fertility 95 231-248

Renfree MB and Calaby JH (1981) Background to delayed implantation and embryonic diapause Journal of Reproduction and Fertility Supplement 29 1-9
Sadlier RMFS (1969) The Ecology of Reproduction in Wild and Domestic Mammals Methuen \& Co Ltd, London

Sapkal VM and Bhandarkar WR (1984) Breeding habits and associated phenomena in some Indian bats. Part IX - Hipposideros lankadiva (Kelaart) Hipposideridae Journal, Bombay Natural History Society 81 380-386

Storrs EE, Burchfield HP and Rees RJW (1988) Superdelayed parturition in armadillos: a new mammalian survival strategy Leprosy Review 59 11-15

Widmaier EP and Kunz TH (1993) Basal, diurnal, and stress-induced levels of glucose and glucocorticoids in captive bats Journal of Experimental Zoology 265 533-540

Widmaier EP, Harmer TL, Sulak AM and Kunz, TH (1994) Further characterization of the pituitary-adrenocortical responses to stress in Chiroptera Journal of Experimental Zoology 269 442-449

Willig MR (1985) Reproductive patterns of bats from Caatingas and Cerrado Biomes in Northeast Brazil Joumal of Mammalogy 66 668-681

Wimsatt WA (1975) Some comparative aspects of implantation Biology of Reproduction $121-40$ 